\title{
Dilema Hukum Keluarga Di Indonesia \\ (Studi Analisis Kasus Perceraian Di Indonesia)
}

\author{
Qurrotul Ainiyah, Imam Muslih \\ STIT Al-Urwatul Wutsqo Jombang \\ q_ainiy@yahoo.co.id
}

\begin{abstract}
In marital legislation in Indonesia, divorce is declared valid if it is done in front of a Religious Court judge. Due to ignorance about the law, due process and high costs, some cases prove divorce is only carried out by husband and wife without going through a divorce process in the Religious Courts. So that, legally, their marital status is still valid, despite the fact that they are divorced. This also affects the Iddah period that must be lived by the ex-wife and when the ex-wife can remarry with another man. In fact, after the divorce sighot was said, the ex-wife automatically carried out her Iddah obligations. But in formal law, Iddah will only be served after the fall of the divorce decision by the Religious Court judge. Such conditions can result in legal uncertainty among Muslims in Indonesia.
\end{abstract}

\section{Keywords: Divorce, Marriage Law in Indonesia}

\section{A. PENDAHULUAN}

Perceraian atau putusnya perkawinan adalah terputusnya ikatan perkawinan antara seorang pria dengan seorang wanita. putusnya ikatan tersebut dapat diakibatkan oleh salah seorang diantara keduanya meninggal dunia, antara pria dan wanita bercerai, dan salah seorang diantara keduanya sudah pergi meninggalkan kediamannya sehingga pengadilan menganggap bahwa yang bersangkutan sudah meninggal (Zainuddin Ali, 2006: 73).

Perceraian berasal dari kata "cerai". Menurut Kamus Besar Bahasa Indonesia "cerai" merupakan kata kerja yang berarti pisah, putus hubungan sebagai suami istri. Dalam istilah ilmu Fikih, perceraian dikenal dengan sebutan "talak" atau "Furqah". Talak berarti membuka ikatan atau membatalkan perjanjian atau segala bentuk perceraian yang dijatuhkan oleh pihak suami. Terjadinya perceraian berdampak pada beberapa hal, antara lain kewajiban Iddah bagi isteri, hak Ruju' bagi suami, kewajiban nafkah atas anak dan lain sebagainya.

Hukum Islam mengatur bahwa ketika sang suami yang mengucapkan sighot talak, maka secara otomatis talak telah jatuh/sah, mereka sudah bukan lagi suami isteri, isteri wajib menjalani masa Iddah (kecuali cerai qobla al-dukhul), dan selama isteri dalam masa Iddah, maka suami punya hak untuk meruju'nya (kembali menjadi suami isteri tanpa akad nikah baru). Berbeda dengan hukum Islam, maka dalam hukum perkawinan bagi umat Islam di Indonesia mengaturnya bahwa perceraian dinyatakan 
sah jika dilaksanakan di depan hakim Pengadilan Agama. Sehingga sangat mungkin terjadi suami mencerai isterinya dengan mengucapkan kata-kata Talak yang tidak dilakukan di depan hakim Pengadilan Agama. Ini bisa terjadi mungkin karena ketidakfahaman atas adanya aturan perundang-undangan, atau mungkin karena tidak adanya biaya untuk pengurusan administrasi di Pengadilan Agama. Kondisi yang seperti ini berpengaruh pada kewajiban Iddah yang harus ditunaikan oleh mantan istrinya. Apakah Iddah isteri dilakukan setelah suami mengucapkan sighot Talak dihadapan isteri ataukan setelah diputuskan di hadapan majelis hakim di Pengadilan Agama ?, padahal ketika sang isteri akan menikah dengan laki-laki lain, harus sudah selesai masa Iddahnya. Hal ini berakibat pada ketidak pastian hukum bagi warga negara Indonesia yang beragama Islam, apakah cukup dengan mengikuti aturan hukum agamanya ataukah juga mengikuti aturan hokum negara (hukum posotif).

Ini adalah penelitian literer dengan pendekatan perbandingan (Comparative Approach) yang dikategorikan perbandingan formal (Formelle Rechstvergleichung) yaitu melakukan penelitian dengan perbadingan berdasarkan penelitian pada sumbersumber hukum, atau melihat berbagai system yang berbeda dari peraturan hokum dan kebiasaan serta berbagai teknik untuk melakukan interpretasi terhadap peraturanperaturan hokum (Hajar M, 2017: 85). Hasil penelitian ini diharapkan memberi manfaat kepada perkembangan penerapan hukum formal di Indonesia yang lebih dapat memberikan kepastian hukum dan kenyamanan bagi warga negaranya.

\section{B. KAJIAN TEORI}

1. Hukum Perceraian dalam Islam

Perceraian berasal dari kata cerai yang dalam Islam dikenal dengan istilah Talak. Menurut bahasa talak berarti melepas tali, membebaskan. Sedangkan menurut istilah melepas teli nikah dengan lafal talak atau sesamanya. Lafal talak telah ada sejak zaman jahiliyah. Syara' datang untuk menguatkannya bukan secara spesifik atas umat ini Penduduk jahiliyah menggunakannya ketika melepas tanggungan, tetapi dibatasi maksimal tiga kali (Abdul Aziz Muhammad Azzam dan Abdul Wahhab Sayyed Hawwas, 2015: 255), Hal ini berdasarkan Al Quran, surat Al-Baqarah (2) : 230

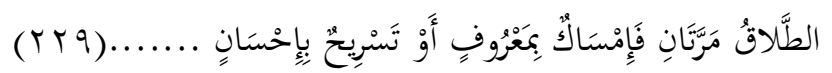

Artinya: Talak (yang dapat dirujuki) dua kali. setelah itu boleh rujuk lagi dengan cara yang ma'ruf atau menceraikan dengan cara yang baik. (Departemen Agama Republik Indonesia, Mushaf Famy bi Syauqin, 2018:3) Sedangkan dalam Hadits Nabi SAW dijelaskan :

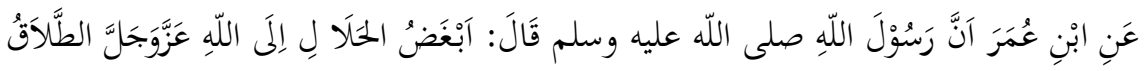

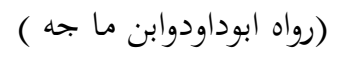

Artinya: Dari Ibnu Umar r.a ia berkata, Rasulullah SAW bersabda: “ Perbuatan halal yang sangat dibenci Allah adalah talak. (H.R Abu Dawud, Ibnu Majah). 
Berdasarkan ayat Al-Qur'an dan Hadits di atas dapat diketahui, bahwa syari'at talak diperbolehkan dalam Islam walaupun itu dibenci (makruh) oleh Allah dan merupakan pintu darurat yang bias dilakukan ketika langkah perdamaian tidak bisa lagi ditempuh. Perceraian ini dinyatakan sah jika terpenuhi rukun dan syaratnya, salah satu rukunnya adalah adanya sighot thalaq yang diucapkan oleh suami kepada istrinya, baik Sighot / ucapan, ini bisa berupa ucapan yang sorih/jelas atau juga kinayah/sindiran.

Ucapan sharih: yaitu ucapan yang tegas, maksudnya untuk menthalaq. Thalaq itu jatuh jika seseorang telah mengucapkan dengan sengaja. Ucapan yang kinayah: yaitu ucapan yang tidak jelas, yang masih memerlukan kejelasan tentang arti dan maksudnya. Ucapan thalaq kinayah memerlukan adanya niat, artinya jika ucapan thalaq itu dengan niat, sah thalaqnya dan jika tidak disertai niat maka thalaqnya belum jatuh.

2. Hukum Perceraian Umat Islam di Indonesia

Hukum perceraian bagi umat Islam di Indonesia diatur dalam beberapa undangundang yaitu :

a. Undang-undang Nomor 1 Tahun 1974 tentang Hukum Perkawinan di Indonesia. Pasal 39 : Perceraian hanya dapat dilakukan di depan Sidang Pengadilan setelah Pengadilan yang bersangkutan berusaha dan tidak berhasil mendamaikan kedua belah pihak.

b. Peraturan Pemerintah Nomor 9 Tahun 1975 tentang Pelaksanaan Undangundang Nomor 1 tahun 1974,

Pasal 14 : Cerai talak yaitu cerai yang dijatuhkan suami di depan Pengadilan yang sesuai dengan hukum Islam

c. Intruksi Presiden Nomor 1 tahun 1991 tentang Kompilasi Hukum Islam di Indonesia.

Pasal 117 : "Perceraian adalah ikrar suami di hadapan Pengadilan Agama yang menjadi sebab putusnya perkawinan".

Pasal 129 : "Seorang suami yang akan menjatuhkan talak kepada istrinya mengajukan permohonan baik lisan maupun tertulis kepada Pengadilan Agama yang mewilayahi tempat tinggal istri disertai dengan alasan serta meminta agar diadakan sidang untuk keperluan itu".

Berdasarkan pasal-pasal di atas dapatlah diketahui bahwa perceraian yang diakui oleh negara kesahannya adalah dilakukan di depan sidang Pengadilan Agama juga harus sesuai dengan syari'at Islam. Ini berarti jika dilaksanakan tidak di depan sidang Pengadilan Agama maka tidak sah walaupun sudah sah menurut hukum Islam. Dualisme pemberlakuan pelaksanaan perceraian ini juga akan berpengaruh pada pelaksanaan Iddah (masa menunggu) isteri untuk bias menikah lagi dengan laki-laki lain. 
3. Iddah

Iddah menurut bahasa berasal dari kata " al- 'udd" dan " al-Ihsha" " yang berarti bilangan atau hitungan, misalnya bilangan harta atau hari jika dihitung satu per satu dan jumlah keseluruhanya. Firman Allah dalam Al-Qur'an, surat al-Taubah (9) : 36

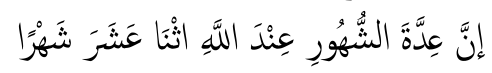

"Sesungguhnya bilangan bulan pada sisi Allah ialah dua belas bulan". (Departemen Agama Republik Indonesia, Mushaf Famy bi Syauqin, 2018:192)

Menurut istilah Fuqaha' Iddah berarti masa menunggu wanita sehingga halal bagi menikah dengan laki-laki lain. Dari pengertian di atas kami dapat diambil kesimpulan bahwa Iddah ialah masa menanti atau menunggu yang diwajibkan atas seorang perempuan yang diceraikan oleh suaminya (cerai hidup atau cerai mati), tujuannya, guna atau untuk mengetahui kandungan perempuan itu berisi (hamil) atau tidak, serta untuk menunaikan satu perintah dari Allah SWT.

Disyariatkannya Iddah berdasar pada al-Qur'an :

a. Surat Al-Baqarah (2) : 228

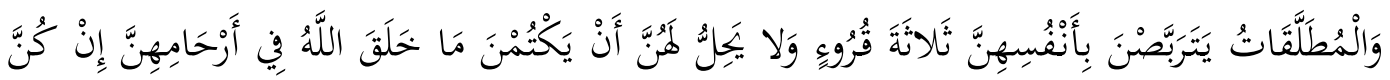

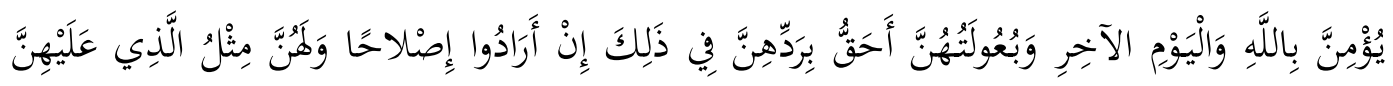

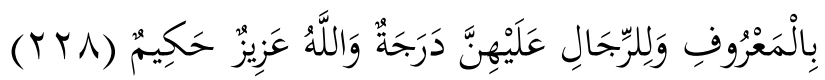

"Wanita-wanita yang ditalak handaklah menahan diri (menunggu) tiga kali quru' tidak boleh mereka Menyembunyikan apa yang diciptakan Allah dalam rahimnya, jika mereka beriman kepada Allah dan hari akhirat. dan suamisuaminya berhak merujukinya dalam masa menanti itu, jika mereka (para suami) menghendaki ishlah. dan Para wanita mempunyai hak yang seimbang dengan kewajibannya menurut cara yang ma'ruf. akan tetapi Para suami, mempunyai satu tingkatan kelebihan daripada isterinya dan Allah Maha Perkasa lagi Maha Bijaksana”. (Departemen Agama Republik Indonesia, Mushaf Famy bi Syauqin, 2018:36)

b. Surah Al Baqarah (2) : 234

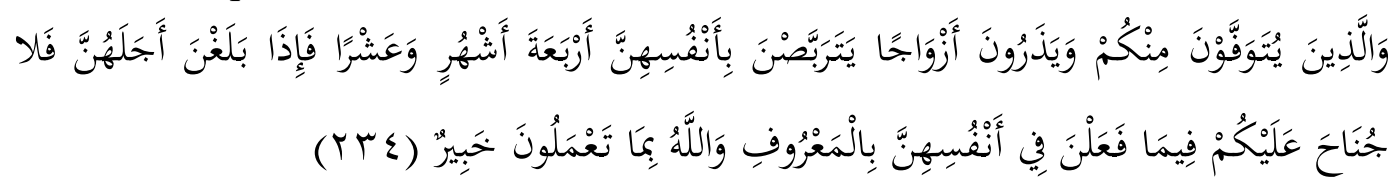

"Orang-orang yang meninggal dunia di antaramu dengan meninggalkan isteriisteri (hendaklah Para isteri itu) menangguhkan dirinya (ber'iddah) empat bulan sepuluh hari. kemudian apabila telah habis 'iddahnya, Maka tiada dosa bagimu (para wali) membiarkan mereka berbuat terhadap diri mereka menurut yang patut. Allah mengetahui apa yang kamu perbuat”. (Departemen Agama Republik Indonesia, Mushaf Famy bi Syauqin, 2018:38) 
c. Surah Al ahzab (33) : 49

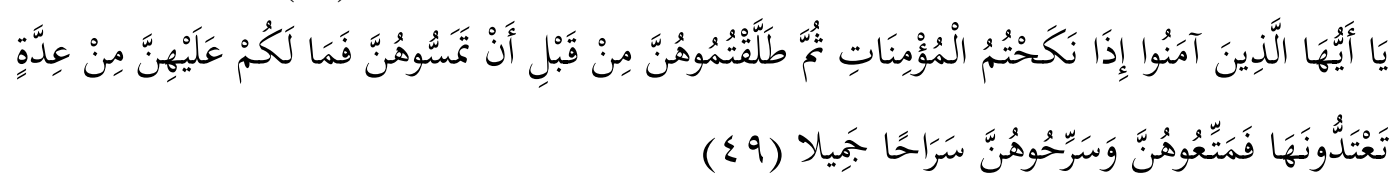

"Hai orang-orang yang beriman, apabila kamu menikahi perempuan- perempuan yang beriman, kemudian kamu ceraikan mereka sebelum kamu mencampurinya Maka sekali-sekali tidak wajib atas mereka 'iddah bagimu yang kamu minta menyempurnakannya. Maka berilah mereka mut'ah dan lepaskanlah mereka itu dengan cara yang sebaik- baiknya”. (Departemen Agama Republik Indonesia, Mushaf Famy bi Syauqin, 2018:424)

\section{Macam-Macam Iddah Perceraian}

a. Iddah perempuan haid yaitu tiga kali masa suci. Berdasarkan surah al Baqarah (2): 228

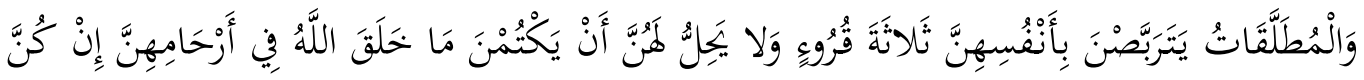

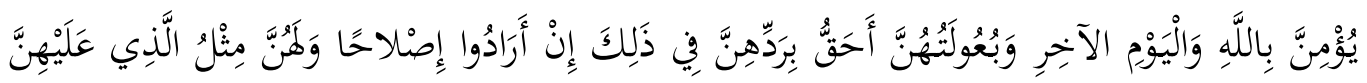

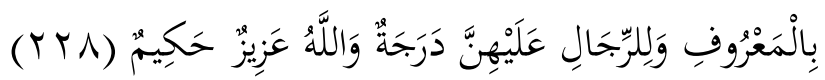

“ wanita-wanita yang ditalak handaklah menahan diri (menunggu) tiga kali quru' tidak boleh mereka Menyembunyikan apa yang diciptakan Allah dalam rahimnya, jika mereka beriman kepada Allah dan hari akhirat. dan suamisuaminya berhak merujukinya dalam masa menanti itu, jika mereka (para suami) menghendaki ishlah. dan Para wanita mempunyai hak yang seimbang dengan kewajibannya menurut cara yang ma'ruf. akan tetapi Para suami, mempunyai satu tingkatan kelebihan daripada isterinya. dan Allah Maha Perkasa lagi Maha Bijaksana”. (Departemen Agama Republik Indonesia, Mushaf Famy bi Syauqin, 2018:38)

b. Iddah perempuan tidak haid yaitu tiga bulan sesuai Al-Qur'an surah at Thalaq (65): 4

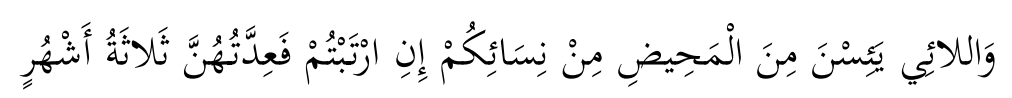

"Dan perempuan-perempuan yang tidak haid lagi (monopause) di antara perempuan-perempuanmu jika kamu ragu-ragu (tentang masa iddahnya), Maka masa iddah mereka adalah tiga bulan; dan begitu (pula) perempuan-perempuan yang tidak haid”. (Departemen Agama Republik Indonesia, Mushaf Famy bi Syauqin, 2018:558) 
c. Iddah perempuan hamil yaitu sampai melahirkan berdasarkan surah at Thalaq (65): 4

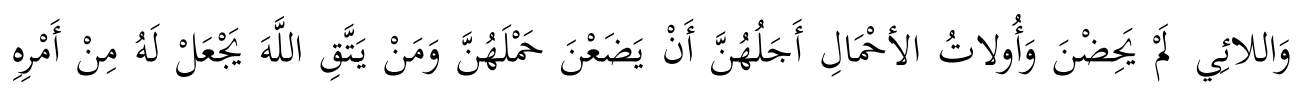

يُسْرًا (ع)

"Dan perempuan-perempuan yang hamil, waktu iddah mereka itu ialah sampai mereka melahirkan kandungannya. dan barang -siapa yang bertakwa kepada Allah, niscaya Allah menjadikan baginya kemudahan dalam urusannya". (Departemen Agama Republik Indonesia, Mushaf Famy bi Syauqin, 2018:558)

\section{HASIL PENELITIAN}

Suatu hukum disusun tidak terlepas dari asas-asas yang mendukungnya. Oleh karena itu hukum sebagai suatu sistem, maka susunan atau tataan teratur yang terdiri dari aturan-aturan hidup, keseluruhannya terdiri atas bagian-bagian yang berkaitan satu sama lain. Seharusnya dalam sistem hukum yang baik tidak boleh terjadi pertentangan di antara bagian-bagian yang ada. Jika terjadi suatu aturan bertentangan atau kontradiksi, maka fungsi dan tujuan diberlakukannya hukum tidak akan terwujud.

Fungsi hukum adalah, sebagai Fungsi Perlindungan, yaitu hukum melindungi masyarakat dari ancaman bahaya; Fungsi Keadilan, yaitu hukum sebagai penjaga, pelindung dan memberikan keadilan bagi manusia; dan fungsi dalam Pembangunan, yaitu hukum dipergunakan sebagai acuan tujuan negara. Sedangkan tugas

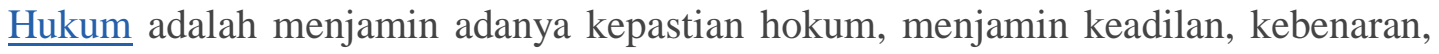
ketentraman dan perdamaian; dan enjaga jangan sampai terjadi perbuatan main hakim sendiri dalam pergaulan masyarakat.

Seorang suami yang beragama Islam yang akan menceraikan isterinya, maka dianggap sah jika diucapkan oleh suami sah atas isteri sahnya, dengan lafadh cerai atau yang dipahami sebagai cerai, suami yang mencerai berakal, baligh dan bebas (tidak dalam tekanan/paksaan). Hal ini menunjukkan dalam ikrar talak/cerai tidak disyaratkan adanya saksi. Fuqoha' yang berpendapat tidak disyaratkannya saksi dalam perceraian adalah dengan dasar bahwa cerai itu adalah hak suami sehingga tidak diperlukan saksi dalam pemenuhan haknya tersebut ((Sayyid Sabiq,1980: 33)

Tetapi beberapa fuqoha' lain berpendapat bahwa dalam perceraian disyaratkan adanya saksi, yaitu Ali bin Abi Thalib, Imran bin Husein, Ja'far Ash-Shidieq dan dari kalangan Tabi'in. Pendapat mereka didasarkan pada isi surat Ath-Thalaq (65) : 2, (Departemen Agama Republik Indonesia, Mushaf Famy bi Syauqin, 2018:558)

Dhahir Ayat di atas menunjukkan bahwa jika terjadi perceraian kemudian mendekati akhir masa iddah dan berkehendak untuk merujuknya atau melepaskan/mencerainya, maka ceraikan dengan cara yang baik dan dengan dipersaksikan oleh 2 (dua) orang yang adil. Sehingga adanya 2 saksi juga menjadi syarat sah dalam cerai dan ruju' sebagaimana juga disyaratkan dalam pernikahan. Jika 
dhahir ayat menunjukkan pada perinah yang berarti wajib, maka mengartikan dengan hukum sunnah adalah menyalahi ketentuan hukum agama, kecuali ada dali-dali kuat yang menerangkannya. Bahkan Ja'far Ash-Shiddieq berkata bahwa barang siapa yang mentalaq tanpa menghadirkan saksi, maka tidaklah berarti Talaqnya (Sayyid Sabiq,1980: 33). Pendapat ini juga dikuatkan dalam kitab Tafsir Ibnu Katsir yang menyatakan bahwa nikah, talaq dan Ruju' tidak diperbolehkan tanpa adanya 2 orang saksi yang adil sesuai dengan bunyi surat Ath-Thalaq (65) ayat 2 di atas. Lebih jauh dijelaskan bahwa kewajiban adanya 2 orang saksi dalam talaq bukan hanya dikemukakan oleh Ulama dari kalangan Rasulullah saja tetapi juga oleh ATha', Ibnu Sirrin serta Ibnu Juraij (Sayyid Sabiq,1980: 33).

Bagi umat Islam yang hidup di Indonesia diberlakukan 2 (dua) aturan hukum perceraian, yaitu hukum Islam (fikih) dan Undang-undang pernikahan yang meliputi undang-undang Nomor 1 tahun 1974 tentang perkawinan di Indonesia, Peraturan Pemerintah Nomor 9 tahun 1975 tentang Pedoman Pelaksanaan Undang-undang perkawinan di Indonesia, dan Instruksi Presiden Nomor 1 tahun 1991 tentang Kompilasi Hukum Islam di Indonesia.

Apabila orang laki-laki/suami muslim warga negara Indonesia akan menceraikan isterinya, maka berdasarkan bunyi Peraturan Pemerintah Nomor 9 Tahun 1975 tentang Pelaksanaan Undang-undang Nomor 1 tahun 1974, dalam Pasal 14 yang berbunyi Cerai talak yaitu cerai yang dijatuhkan suami di depan Pengadilan yang sesuai dengan hukum Islam, maka ditemukan dua macam hukum yang harus dipenuhi agar perceraian itu sah. Tetapi dua hukum itu isi aturannya berbeda/tidak sama.

1. Berdasarkan hukum Islam (Fikih), maka suami dapat (sah) menceraikan isterinya dengan mengucapkan sighat Talak di hadapan isterinya.

2. Menurut perundang-undangan di Indonesia maka perceraian baru dinyatakan sah jika sah menurut hukum agama dan diucapkan dihadapan Hakim Pengadilan Agama. Artinya jika proses perceraian tidak dilaksanakan di hadapan hakim Pengadilan Agama, maka perceraian itu dianggap tidak sah atau tidak mempunyai kekuatan hukum, sehingga pernikahannya dianggap masih tetap sah.

Sedangkan fakta di lapangan terjadi beberapa contoh kasus perceraian :

1. Perceraian yang dilakukan oleh suami atas isterinya dengan mengucapkan sighat Talak di depan isteri, ini menurut hukum Perkawinan di Indonesia, perceraian itu belum sah, karena proses perceraian dan pengucapan sighat Talak tersebut tidak dilakukan di depan sidang Pengadilan Agama, sehingga jika mereka akan melangsungkan pernikahan dengan pasangan barunya, maka tidak bisa dicatat di Kantor Urusan Agama (KUA) karena tidak mempunyai akte cerai yang dikeluarkan oleh Pengadilan Agama sebagai syarat yang harus dilampirkan ketika duda/janda akan menikah lagi.

2. Ketika pasangan suami isteri yang bercerai secara Islam kemudian memproses perceraiannya di Pengadilan Agama, maka ketika mantan isteri akan melangsungkan pernikahan, maka harus menunggu sampai selesai menjalankan 
iddah kembali terhitung setelah putusan cerai dikeluarkan oleh Pengadilan Agama. Hal ini berarti mantan isteri menjalankan dua kali masa Iddah.

Agar perceraian bisa lebih cepat dilaksanakan maka terkadang seorang suami akan mengambil jalan pintas yaitu bercerai secara fiqh atau hukum Islam yang selama ini telah biasa terjadi pada masyarakat tanpa melalui prosedur yang perceraian di hadapan hakim pengadilan agama sebagaimana yang diatur dalam UU perkawinan di Indonesia dan Kompilasi Hukum Islam di Indonesia. Hal ini membuktikan bahwa adanya dualisme hukum kehidupan masyarakat. Kondisi ini masih banyak dilaksanakan secara terang-terangan dan masih diterima oleh masyarakat bahwa perceraian secara hukum Islam klasik (fiqh) masih eksis dan tetap menjadi alternatif pilihan hukum dalam perceraian karena praktis, cepat dan murah (tanpa ada biaya), walaupun secara hukum positif perceraian tersebut tidak mempunyai kepastian hukum, sehingga secara hukum perceraian itu tidak sah dan hubungan suami-isteri masih terikat dalam pernikahan yang sah.

Berdasarkan uraian di atas, Undang-undang No. 1 tahun 1974 dan Kompilasi Hukum Islam di Indonesia mensyaratkan adanya proses perceraian di depan hakim Pengadilan Agama, memberi kesan :

1. Mempersulit terjadinya perceraian di Indonesia, agar tidak mudah terjadi perceraian sehingga dapat menekan laju angka perceraian.

2. Mensyaratkan adanya saksi sebagai syarat sahnya perceraian.

3. Memberikan perlindungan hukum dan kemaslahatan bagi kaum perempuan (isteri) yang ditalak dan anak-anaknya, karena dengan adanya keharusan ikrar talak dilaksanakan/diucapkan di hadapan Hakim Pengadilan Agama tidak membuat seorang suami berlaku semena- mena atas talak yang diucapkan,

4. karena ada proses pemeriksaan dan adanya saksi sehingga lebih dapat dipertanggungjawabkan secara hukum.

5. Ketetapan 'Iddah diberlakukan bagi mantan isteri mengikuti ketetapan talaknya.

\section{KESIMPULAN}

1. Terdapat dualisme hukum keluarga di Indonesia, yaitu hukum Islam (fikih) dan hukum Perkawinan di Indoneia termasuk didalamnya Kompilasi Hukum Islam di Indonesia. Yang secara kenyataan terjadi dan menimbulkan ketidakpastian hukum bagi masyarakat Islam di Indonesia, termasuk di dalamnya adalah hukum perceraian bagi umat Islam di Indonesia.

2. Dualisme hukum perceraian ini membawa pengaruh pada kepastian penghitungan masa Iddah bagi mantan isterinya dan juga akan berakibat pada masa kapan sang mantan isteri tersebut bisa menikah lagi.

3. Kondisi ini seharusnya menjadi bahan pertimbangan bagi pejabat penyusun perundang-undangan untuk dapat merumuskan perundang-undangan yang lebih dapat menjamin kepastian hukum bagi masyarakat pengguna hukum. 
Terakreditasi Nasional Sinta 4: SK. No.30/E/KPT/2019

\section{DAFTAR PUSTAKA}

Ali, Zainuddin. (2006). Hukum Perdata di Indonesia, Jakarta: Sinar Grafika.

Azzam, Abdul Aziz Muhammad dan Abdul Wahhab Sayyed Hawwas.(2015). Fiqh Munakahat, Jakarta: Amzah.

Hajar M. (2017). Model-model Pendekatan dalam Penelitian Hukum dan Fiqh, Yogyakarta : Kalimedia.

Sabiq, Sayyid. (1980). Fikih Sunnah, Jilid 8, terjemahan Mohammad Thalib, Bandung : PT. Al-Ma'arif.

Subki, Ali Yusuf As. (2012). Fiqh keluarga, Jakarta: Amzah. 